\title{
Visualization of the formation and features of soil arching within a piled embankment by discrete element method simulation*
}

\author{
Han-jiang LAI, Jun-jie ZHENG ${ }^{\dagger \ddagger}$, Rong-jun ZHANG, Ming-juan CUI \\ (Institute of Geotechnical and Underground Engineering, Huazhong University of Science and Technology, Wuhan 430074, China) \\ †E-mail: zhengjj@hust.edu.cn \\ Received Nov. 4, 2015; Revision accepted Feb. 18, 2016; Crosschecked Sept. 12, 2016
}

\begin{abstract}
Piled embankments are widely used in highway and railway engineering due to their economy and efficiency in overcoming several issues encountered in constructing embankments over weak soils. Soil arching, caused by the pile-subsoil relative displacement $(\Delta s)$, plays an important role in reducing the embankment load falling on weak soil, however, the fundamental characteristics (e.g., formation and features) of soil arching remain poorly understood. In this study, a series of discrete element method (DEM) modellings are performed to study the formation and features of soil arching with the variation of $\Delta s$ in piled embankments with or without geosynthetic reinforcement. Firstly, calibration for the modelling parameters is carried out by comparing the DEM results with the experimental data obtained from the existing literature. Secondly, the analysis of the macroand micro-behaviours is performed in detail. Finally, a parametric study is conducted in an effort to identify the influences of three key factors on soil arching: the friction coefficient of the embankment fill $(f)$, the embankment height $(h)$, and the pile clear spacing $(s-a)$. Numerical results indicate that $\Delta s$ is a key factor governing the formation and features of soil arching in embankments. To be specific, soil arching gradually evolves from two inclined shear planes at a small $\Delta s$ to a hemispherical arch at a relatively large $\Delta s$. Then, with a continuous increase in $\Delta s$, the soil arching height gradually increases and finally approaches a constant value of $0.8(s-a)$ (i.e., the maximum soil arching height). For a given case, the higher the soil arching height, the greater the degree of soil arching effect. The parametric study shows that the friction coefficient of the embankment fill has a negligible influence on the formation and features of soil arching. However, embankment height is a key factor governing the formation and features of soil arching. In addition, pile clear spacing has a significant effect on the formation of soil arching, but not on its features.
\end{abstract}

Key words: Piled embankment, Numerical simulation, Discrete element method (DEM), Soil arching, Formation, Features http://dx.doi.org/10.1631/jzus.A1500302

CLC number: U213.11

\section{Introduction}

Piled embankments, with or without geosynthetic reinforcement, have been widely used to overcome several issues (e.g., insufficient bearing capacity, local instability, and unacceptable settle-

\footnotetext{
${ }^{\ddagger}$ Corresponding author

* Project supported by the National Key Research and Development Program of China (2016YFC0800208) and the National Natural Science Foundation of China (Nos. 51278216, 51478201, 51308241, and 51608316)

(1D) ORCID: Han-jiang LAI, http://orcid.org/0000-0003-2845-6002; Jun-jie ZHENG, http://orcid.org/0000-0001-9679-4914

(C) Zhejiang University and Springer-Verlag Berlin Heidelberg 2016
}

ment), encountered in the construction of railways and highways over weak soils (e.g., highly compressible soil, alluvial clay, and peat) (Chen et al., 2010; 2013; 2014; 2016; Ling et al., 2010; Briançon and Simon, 2012; Liu et al., 2012; Wang C. et al., 2014). Soil arching plays a very important role in reducing the embankment load shared by the weak soil between piles, which is essentially a stress redistribution phenomenon caused by the pile-subsoil relative displacement $(\Delta s)$, and has been proven to be a key load-transfer mechanism in embankments. However, the soil arching developed in a piled embankment remains poorly understood (Gabr and Han, 2005; Chen et al., 2008; Lai et al., 2014; Lu and Miao, 
2015), including its most fundamental characteristics (e.g., formation and features). Hence, further studies are required and would be of practical importance in the optimization of relevant design methods.

To help identify the load-transfer mechanism of soil arching in embankments, various assumptions models regarding the features of soil arching have been proposed. Terzaghi (1943) established a 2D soil arching model by the equilibrium equation for relative displacement of embankment fill and considered that the influence height of soil arching was about twice that of the pile clear spacing, but did not mention the arch shape. Guido et al. (1987) proposed a pyramidal model with an inclined angle of $45^{\circ}$ to describe soil arching in embankments, while Carlson (1987) considered that soil arching in embankments was a sphenoid with an apical angle of $30^{\circ}$. Meanwhile, Carlson (1987) and Guido et al. (1987) argued that the subsoil carried the embankment load only below the soil arching and the rest of the embankment load was fully shared by the piles. Depending on laboratory model tests, Hewlett and Randolph (1988) established a semi-spherical model (termed the H\&R model) to depict soil arching in embankments and considered that the ultimate state of soil arching would be reached either at the crown of the arch or just above the pile cap. Kempfert et al. (1997) improved the soil arching model proposed by Hewlett and Randolph (1988) and considered that soil arching in embankments was made up of multiple semispheres with different centres. Furthermore, van Eekelen et al. (2013; 2015) developed a soil arching model with concentric hemispheres based on the models of Hewlett and Randolph (1988) and Zaeske and Kempfert (2002). Meanwhile, Rui et al. (2016a; $2016 \mathrm{~b}$ ) argued that there are three soil arching evolution patterns (i.e., a triangular expanding pattern, a tower-shaped evolution pattern, and an equal settlement pattern) in piled embankments. In summary, the existing soil arching models are quite different from each other, owing to the different assumptions adopted on the features of soil arching in each case. These different models pose some confusion in practical design.

Terzaghi (1943) considered that the relative displacement in embankment fill and the support for the arch feet were the two premises for the formation of soil arching. Obviously, in a piled embankment, the relative displacement in an embankment fill is caused by $\Delta s$ and the piles serve as the support for the arch feet. Meanwhile, existing studies implicitly assumed that the development of soil arching in an embankment would complete with a tiny $\Delta s$. To investigate the influences of $\Delta s$ on the soil arching effect, Chen et al. (2008) conducted a set of laboratory model tests. The experimental results indicated that the degree of the soil arching effect increased gradually with $\Delta s$ and eventually reached a relatively stable state. However, only the variation of soil arching effect with $\Delta s$ on a macroscopic scale was performed in Chen et al. (2008)'s study, and the intrinsic factors (e.g., formation and features of soil arching) causing variation in the soil arching effect were not completely revealed, as seems to be difficult with the macroscopic indices (e.g., soil pressure, settlement, and excess pore water pressure) using the measurements of field or laboratory model tests. Consequently, numerical simulation is necessary to uncover the complicated inherent characteristics of soil arching at a microscopic scale. The finite element method (FEM) and the finite difference method (FDM) have been widely used as numerical tools to model piled embankments (Han and Gabr, 2002; Zhang et al., 2013; Benmebarek et al., 2015), but these methods are based on the continuum assumption and make it difficult to capture the micro-behaviour of granular fill. As an alternative, the discrete element method (DEM), based on the dis-continuum assumption, offers an approach for gaining an insight into the micro-behaviour of granular material. DEM has received increasing attention and popularity over the past decade or more (Jenck et al., 2009; Bhandari and Han, 2010; Han et al., 2012; Lai et al., 2014; Wang Z.J. et al., 2014; 2016) since it addresses the major drawbacks of FEM and FDM.

The objective of this study is to investigate the formation and features of soil arching in piled embankments with or without geosynthetic reinforcement using DEM based on a software called $\mathrm{PFC}^{2 \mathrm{D}}$ (Itasca, 2008). The work presented in this study can be divided into three parts: (1) determining the micromechanical properties of embankment fill and geosynthetic via a series of numerical tests, and calibrating the DEM modelling parameters by comparing the simulation results with the published experimental data; (2) performing detailed investigation on the formation and features of soil arching at both macroscopic and microscopic scales; (3) identifying the influences of some governing factors on soil arching. 


\section{DEM numerical analysis}

\subsection{Description of selected cases}

The fundamental cases conducted in this study are based on the laboratory model tests reported in Chen et al. (2008). The basic information about the model tests is shown in Fig. 1. The maximum embankment height was $1200 \mathrm{~mm}$. $\Delta s$ was simulated by discharging water from the water bags during the tests. The coefficient of uniformity $C_{\mathrm{u}}$ of the sand was 2.5 , and the coefficient of curvature $C_{\mathrm{c}}$ was 0.96 . Other characteristics were $D_{10}=0.1 \mathrm{~mm}, D_{60}=0.25 \mathrm{~mm}$, and $D_{\max }=2 \mathrm{~mm}$. The unit weight of the sand was $15.35-15.83 \mathrm{kN} / \mathrm{m}^{3}$ with a relative density of $(55 \pm 7) \%$.

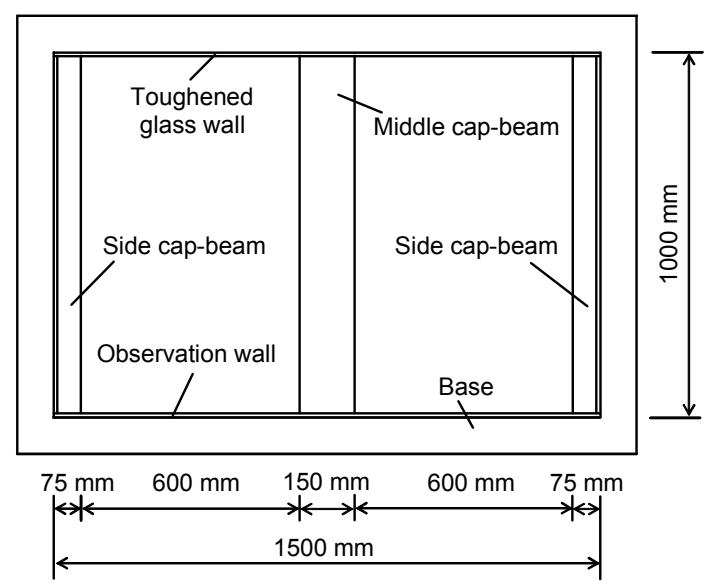

(a)

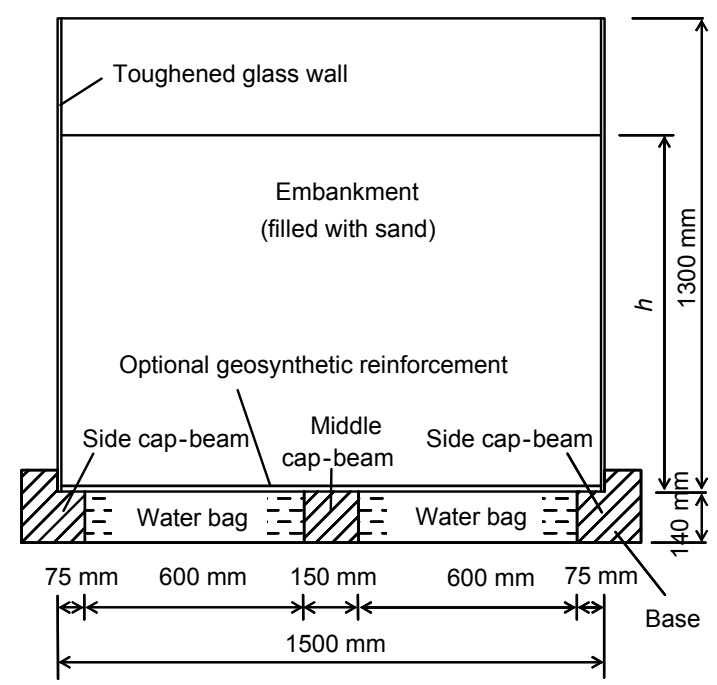

(b)

Fig. 1 Layout of test set up (Chen et al., 2008)

(a) Top view; (b) Side view. $h$ is the embankment height
The peak secant friction angles of the embankment fill were determined by triaxial compression tests to be $45^{\circ}$ and $43^{\circ}$ corresponding to effective confining stresses of $10 \mathrm{kPa}$ and $50 \mathrm{kPa}$, respectively. For the geosynthetic reinforcement case, the geosynthetic (biaxial tensile strength $22.5 \mathrm{kN} / \mathrm{m}$ at $8 \%$ axial strain) was laid just upon the water bags and cap-beams with both ends fixed on the top of the side cap-beams. Detailed information about the tests can be found in Chen et al. (2008).

\subsection{Numerical modelling}

In this study, a 2D simulation using DEM modelling is performed with the software $\mathrm{PFC}^{2 \mathrm{D}}$. Due to the symmetry of the laboratory model (Fig. 1), the computational domain for the simulation is selected on one half of the model and the profile of a numerical embankment over piles is presented in Fig. 2. The rectangular box and piles are simulated by walls, and the embankment fill is modelled by particles. The improved multi-layer compaction method (Lai et al., 2014) is utilized to obtain a dense and homogeneous assembly, and the thickness of each layer is selected as $100 \mathrm{~mm}$, which is consistent with the sand filling procedure in the laboratory model tests. A half of the pile $(0.075 \mathrm{~m} \times 0.20 \mathrm{~m})$ is placed on both sides below the embankment. For the geosynthetic reinforcement case, a geosynthetic sheet which is modelled by the parallel bonded particles is first placed upon the piles with both end particles fixed upon piles, and then the embankment fill particles are generated upon the

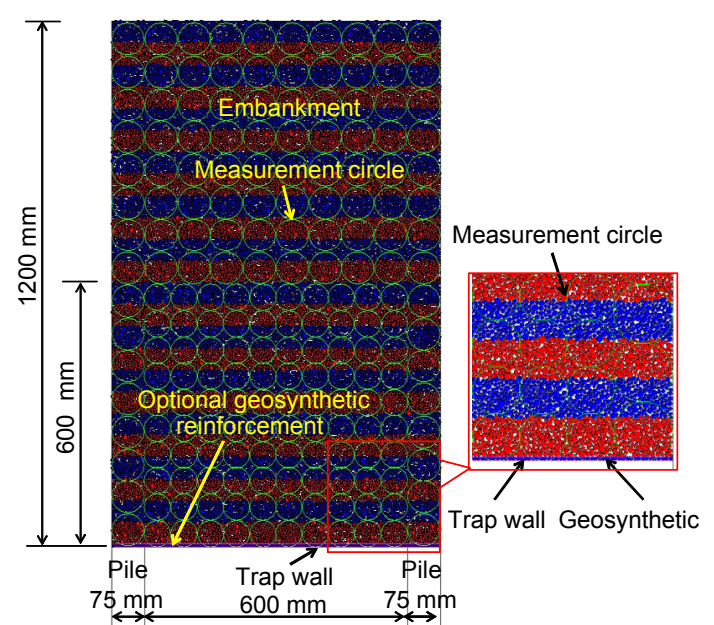

Fig. 2 DEM model of a piled embankment with an optional geosynthetic reinforcement 
geosynthetic. $\Delta s$ is simulated by moving the trap wall at the bottom of the embankment (Fig. 2) with a constant velocity of $0.001 \mathrm{~m} / \mathrm{s}$. The stress state, which is a continuum quantity, can be obtained by a measurement circle using the volume average method. Thus, a series of measurement circles are laid in the embankment to record the variation of stress state during the simulation.

\subsection{Determination of the input parameters}

\subsubsection{Embankment fill properties}

The properties of embankment fill have been calibrated by numerical biaxial tests (Jenck et al., 2009; Bhandari and Han, 2010; Han et al., 2012; Lai et al., 2014). A set of un-bonded particles with diameters ranging from $4.0 \mathrm{~mm}$ to $7.0 \mathrm{~mm}$ are generated at a porosity of 0.16 under the gravity deposition method. Then, different confining stresses $(10 \mathrm{kPa}$, $25 \mathrm{kPa}$, and $50 \mathrm{kPa}$, respectively) are applied to the assembly by a numerical servo-mechanism. Fig. 3 presents the deviatoric stress versus axial strain which is obtained by numerical biaxial tests using $\mathrm{PFC}^{2 \mathrm{D}}$. Following the recommendations of Bolton (1986), the peak secant angle of shearing resistance, $\varphi_{\max }$, can be determined as $45.20^{\circ}, 43.35^{\circ}$, and $41.09^{\circ}$, corresponding to the confining stresses of $10 \mathrm{kPa}, 25 \mathrm{kPa}$, and $50 \mathrm{kPa}$, respectively. Overall, $\varphi_{\max }$ agrees well with that of the sand used in the laboratory model tests (Chen et al., 2008), and the corresponding micromechanical properties of the particles are summarized in Table 1.
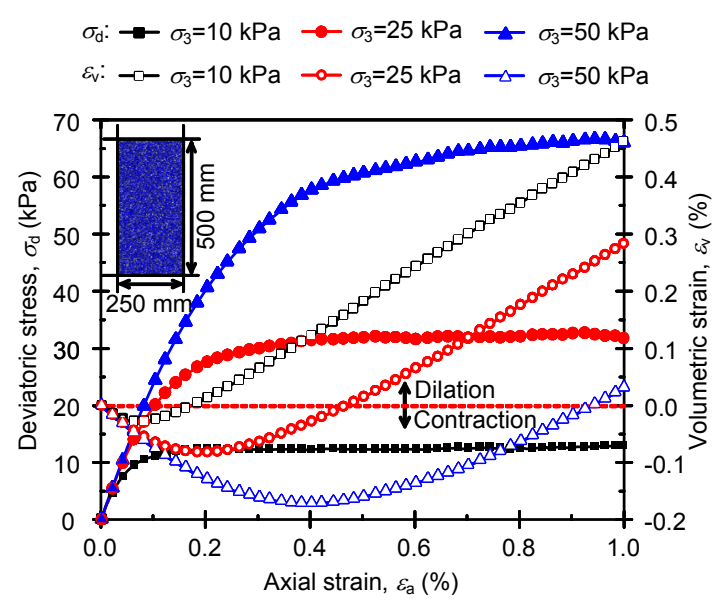

Fig. 3 Deviatoric stress versus axial strain of numerical biaxial tests using $\operatorname{PFC}^{2 \mathrm{D}}$ ( $\sigma_{3}$ is the confining stress)
Table 1 Micromechanical properties for the DEM analysis

\begin{tabular}{lc}
\hline \multicolumn{1}{c}{ Parameter } & Value \\
\hline Embankment fill & \\
Normal stiffness of particle, $k_{\mathrm{n} \_\mathrm{f}}(\mathrm{N} / \mathrm{m})$ & $7.5 \times 10^{7}$ \\
Shear stiffness of particle, $k_{\mathrm{s} \_\mathrm{f}}(\mathrm{N} / \mathrm{m})$ & $5.0 \times 10^{7}$ \\
Friction coefficient, $\mu_{\mathrm{f}}$ & 0.4 \\
Density of particle, $\rho_{\mathrm{f}}\left(\mathrm{kg} / \mathrm{m}^{3}\right)$ & 2000 \\
\hline Geosynthetic & \\
Normal stiffness of particle, $k_{\mathrm{n} \_\mathrm{g}}(\mathrm{N} / \mathrm{m})$ & $6.45 \times 10^{8}$ \\
Shear stiffness of particle, $k_{\mathrm{s} \_\mathrm{g}}(\mathrm{N} / \mathrm{m})$ & $6.45 \times 10^{8}$ \\
Friction coefficient, $\mu_{\mathrm{g}}$ & 0.4 \\
Density of particle, $\rho_{\mathrm{g}}\left(\mathrm{kg} / \mathrm{m}^{3}\right)$ & 1000 \\
Contact bond normal strength, $\varphi_{\mathrm{n} \_\mathrm{g}}(\mathrm{N})$ & $4.0 \times 10^{5}$ \\
Contact bond shear strength, $\varphi_{\mathrm{s} \_\mathrm{g}}(\mathrm{N})$ & $4.0 \times 10^{5}$ \\
Parallel bond normal stiffness, $k_{\mathrm{np} \_\mathrm{g}}$ & $1.13 \times 10^{10}$ \\
$\quad\left(\mathrm{~N} / \mathrm{m}^{3}\right)$ & \\
Parallel bond shear stiffness, $k_{\mathrm{sp} \_\mathrm{g}}$ & $1.13 \times 10^{10}$ \\
$\left(\mathrm{~N} / \mathrm{m}^{3}\right)$ & \\
Parallel bond normal strength, $\sigma_{\mathrm{np} \_\mathrm{g}}$ & $4.0 \times 10^{10}$ \\
$\quad\left(\mathrm{~N} / \mathrm{m}^{2}\right)$ & \\
Parallel bond shear strength, $\sigma_{\mathrm{sp} \_\mathrm{g}}$ & $4.0 \times 10^{10}$ \\
$\left(\mathrm{~N} / \mathrm{m}^{2}\right)$ & \\
Parallel bond radius multiplier, $r_{\mathrm{pb} \_\mathrm{g}}$ & 1.0 \\
\hline Pile and wall & $6.00 \times 10^{10}$ \\
Normal stiffness, $k_{\mathrm{n} \_\mathrm{w}}(\mathrm{N} / \mathrm{m})$ & $6.00 \times 10^{10}$ \\
Shear stiffness, $k_{\mathrm{s} \_\mathrm{w}}(\mathrm{N} / \mathrm{m})$ & 0.0 \\
\hline Friction coefficient, $\mu_{\mathrm{w}}$ & \\
\hline
\end{tabular}

\subsubsection{Geosynthetic properties}

The properties of the geosynthetic were calibrated by numerical tensile tests (Jenck et al., 2009; Han et al., 2012; Lai et al., 2014). The parallel bond model which can bear tension is used to simulate the geosynthetic. The diameter of the geosynthetic particle is selected as $2 \mathrm{~mm}$. According to JTJ/T 060-98 (MOT, 1999), the total length of geosynthetic for tensile test simulation is selected as $100 \mathrm{~mm}$. With the end particle fixed, a constant horizontal velocity $v$ of $20 \mathrm{~mm} / \mathrm{min}$ is applied to the starting particle to simulate the tensile test. The variation of contact bond force of the starting particle is recorded by the elongation of the geosynthetic. Comparison between DEM and experimental results is shown in Fig. 4 and the corresponding micromechanical parameters of the geosynthetic are presented in Table 1. It can be observed from Fig. 4 that DEM results have a good agreement with the experimental data. 


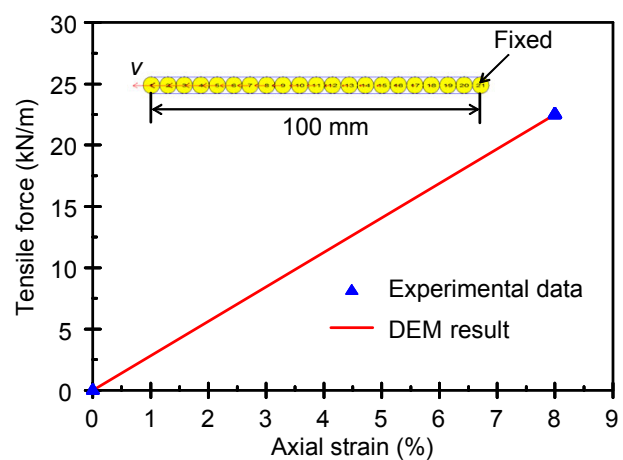

Fig. 4 Comparison between the DEM and experimental results of a geosynthetic in tensile test

\subsection{Modelling parameters calibration}

To ensure the realistic representation of numerical modelling of piled embankments, calibration for the parameters involved in the modelling is verified against the variation of soil pressures acting on pile surface $\left(\sigma_{\mathrm{p}}\right)$ and subsoil $\left(\sigma_{\mathrm{s}}\right)$. Only the comparison between the DEM results and experimental data for the case without geosynthetic reinforcement is presented here (Fig. 5), because the variation of soil pressure with $\Delta s$ for the geosynthetic reinforcement case has not been presented in Chen et al. (2008). In DEM, with an increase in $\Delta s, \sigma_{\mathrm{p}}$ gradually increases from $18.60 \mathrm{kPa}$ to $63.31 \mathrm{kPa}$, and $\sigma_{\mathrm{s}}$ gradually decreases from $18.60 \mathrm{kPa}$ to $7.87 \mathrm{kPa}$. However, in the laboratory model test, $\sigma_{\mathrm{p}}$ increases from $30.81 \mathrm{kPa}$ to $63.97 \mathrm{kPa}$ and $\sigma_{\mathrm{s}}$ decreases from $17.51 \mathrm{kPa}$ to $6.34 \mathrm{kPa}$. Through comparing the soil pressures obtained from DEM and laboratory model tests, it can be found that the variation trends and the maximum (or minimum) values of $\sigma_{\mathrm{p}}\left(\right.$ or $\left.\sigma_{\mathrm{s}}\right)$ are in a good agreement although $\Delta s$ in DEM is smaller than that in the laboratory model tests. An explanation could be that the irregular shape and the rough surface of sand particles cannot be reasonably modelled in $\mathrm{PFC}^{2 \mathrm{D}}$, and as a result, a smaller $\Delta s$ will directly cause greater relative movement of the embankment fill above the pile, which will induce a larger shear stress in the embankment and transfer more load to the piles with a smaller $\Delta s$.

Fig. 5 also shows that, in the initial state (before the water discharge in laboratory model tests or the trap wall moving in DEM, i.e., $\Delta s$ is $0.0 \mathrm{~mm}$, and denoted as $0.01 \mathrm{~mm}$ in Fig. 5), $\sigma_{\mathrm{p}}$ is almost identical to $\sigma_{\mathrm{s}}$ in DEM, while for the laboratory model test, $\sigma_{\mathrm{p}}$ is much greater than $\sigma_{\mathrm{s}}$. Note that $\Delta s$ in the laboratory model tests was simulated by discharging water from water bags. Before the water discharge, a certain $\Delta s$ will inevitably take place during the embankment filling, due to the compressibility and flow ability of the water bags. As a result, the soil pressure at the bottom of the embankment becomes non-uniform and the mean pressure on the pile increases from the "theoretical" value $(18.60 \mathrm{kPa})$ to $30.81 \mathrm{kPa}$, whereas the mean pressure on the subsoil decreases to $17.51 \mathrm{kPa}$. However, in DEM, $\Delta s$ is modelled by moving the trap wall at the bottom of the embankment (Fig. 2), which can be strictly controlled at $0.0 \mathrm{~mm}$ in the initial state. Thus, it is not surprising that no soil arching effect occurs in the initial state of DEM modelling. More importantly, in this way, an accurate $\Delta s$ can be achieved at each stage as requested, which would be useful in tracing the evolution of soil arching with an increase in $\Delta s$.

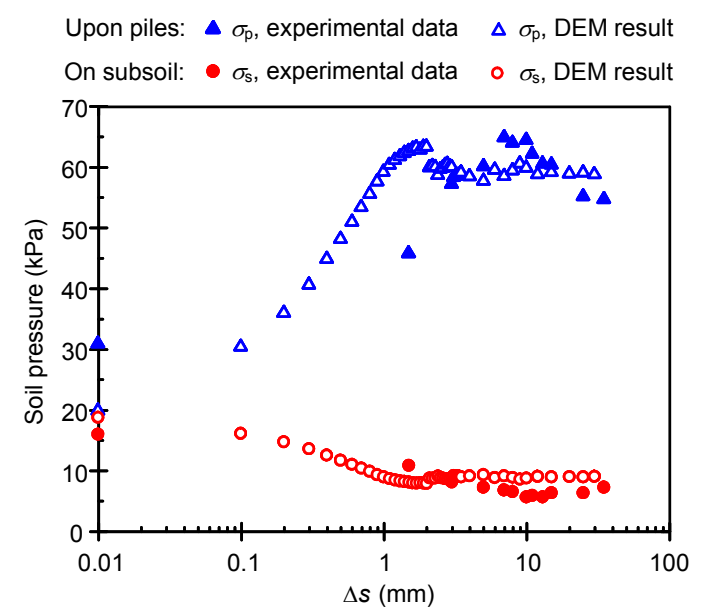

Fig. 5 Variation of soil pressure for piled embankments without geosynthetic reinforcement

\section{DEM analysis of soil arching}

Soil arching in an embankment is, in essence, a stress redistribution phenomenon induced by the relative displacement of the embankment fill, with the load-transfer of soil arching, is achieved through an interconnected network of force chains via contact points. Soil arching is closely related to the status (e.g., number, magnitude, and orientation) of contacts and forces among the embankment fill, which will inevitably be changed by the relative displacement of 
the embankment fill. In this section, the formation and features of soil arching in an embankment will be focused upon via both macroscopic and microscopic behaviours (e.g., particle motion, contact force chains, principal stress direction, and contact and force orientations) in the embankment fill. Meanwhile, DEM modelling of the piled embankments without geosynthetic reinforcement (denoted as unreinforced case) and with geosynthetic reinforcement (denoted as geogrid-reinforced case) will be adopted in the following studies.

\subsection{Characteristics of particle motions}

Essentially, the occurrence of soil arching in an embankment is immediately caused by a relative movement of the embankment fill. Hence, the distribution of the relative movement of embankment fill can be used to identify the features of soil arching in an embankment. Fig. 6 shows the contour of settlement for unreinforced and geogrid-reinforced cases with $\Delta s=2.0 \mathrm{~mm}$. The particles are divided into 16 groups according to the magnitude of settlement. It can be seen from Fig. 6 that the settlement of the particles upon piles is significantly smaller than that of the particles above the subsoil. From the bottom to the top of embankment, the settlement increases upon piles but decreases over the mid-span of the subsoil. Within the lower $480 \mathrm{~mm}$ (i.e., $0.8(s-a)$ ) of the embankment, the settlement of particles clearly varies in



(a)
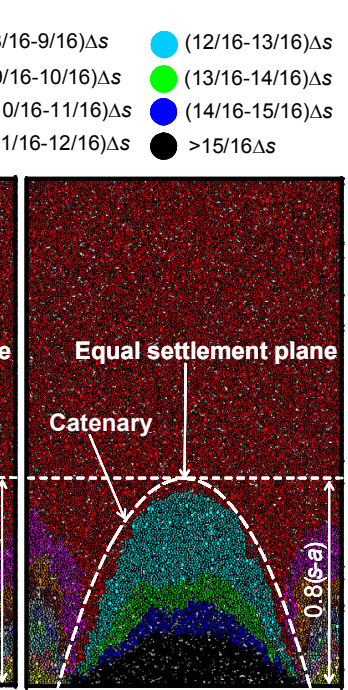

(b)
Fig. 6 Contour of settlement with $\Delta s=2.0 \mathrm{~mm}$ (a) Unreinforced case; (b) Geogrid-reinforced case both the vertical and horizontal directions. Nevertheless, in the upper portion of the embankment, the settlement tends to be uniform, and the corresponding settlement of the whole region is approximately $(8 / 16-9 / 16) \Delta s$. The height of the equal settlement plane (i.e., influence height of soil arching) is approximately equal to $0.8(s-a)$ for both cases. Meanwhile, there is an obvious boundary between the settlements upon the pile head and the mid-span of the subsoil, which approximates to a catenary.

\subsection{Overview of the contact force chains}

Contact force chains are the load-transfer medium in an embankment which are able to visually reflect the state of stress redistribution in it. Hence, the contact force chains can, to some extent, be used to identify the features of soil arching in embankments. Moreover, understanding the contact force chains is helpful in studying the load-transfer mechanism of soil arching in embankments. Fig. 7 shows the distribution of contact forces in unreinforced and geogrid-reinforced cases with $\Delta s=2.0 \mathrm{~mm}$. The contact forces are plotted on the same scale and the line width represents their relative magnitude. It can be observed that the contact force concentrating upon the piles is evident in both cases. The maximum compressive contact forces are $1.13 \mathrm{kN}$ and $1.85 \mathrm{kN}$ in unreinforced and geogrid-reinforced cases, respectively, and the maximum tensile force in the geosynthetic of geogrid-reinforced case occurs at the edge of pile surface with a value of $1.31 \mathrm{kN}$. Moreover, a network of strong contact force (proved to be the contact forces higher than 1.5 times of mean contact force of the whole assembly, referring to Section 3.3.1) gradually aligns in the horizontal direction above the mid-span between piles and forms a "catenary-shaped" arch (referring to the dashed lines in Fig. 7). Meanwhile, the height of the "catenaryshaped" arch is about $0.8(s-a)$ for both cases.

To sum up, on the basis of the variation of soil pressure (Section 2.4) and the characteristics of particle motions (Sections 3.1) and contact force chains (Section 3.2), an inference can be made that the soil arching in a piled embankment is in a catenary shape and the maximum height is approximate $0.8\left(s^{-} a\right)$, greater than $0.5(s-a)$ reported in some existing studies (Hewlett and Randolph, 1988; Kempfert et al., 1997; van Eekelen et al., 2013; 2015). For simplicity, 
an "arching zone" (shown in Fig. 7) is defined here for the following studies.

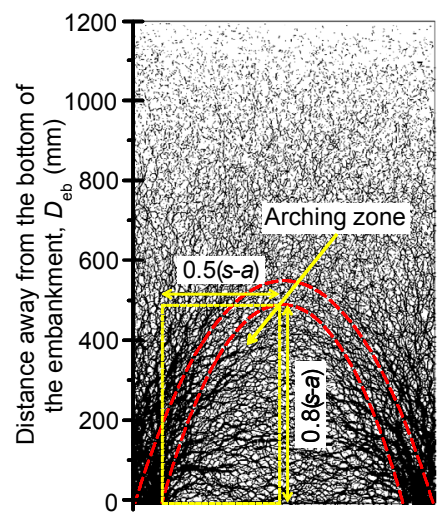

(a)

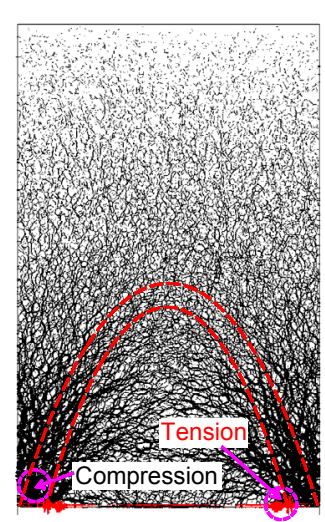

(b)
Fig. 7 Distribution of contact forces with $\Delta s=2.0 \mathrm{~mm}$

(a) Unreinforced case; (b) Geogrid-reinforced case

\subsection{Orientations of contacts and forces}

Clearly, relative movement of embankment fill leads to particle re-arrangement, which inevitably results in some changes in the status (e.g., number, magnitude, and orientation) of contacts and forces (including average, normal, and tangential forces). Fourier series approximation (FSA) (Rothenburg and Bathurst, 1989; Bathurst and Rothenburg, 1990) is a useful statistical approach to identify the changes in contacts and forces in an interest zone with a predefined bin angle. This method offers a good platform for investigating the evolution of soil arching on the microscopic scale with the orientations of contacts and forces, given the difficulty of applying measurements in field/laboratory experiments, or a numerical model based on the continuum assumption or theoretical approaches. In the following studies, FSA is applied for the statistical treatment of contacts and forces, and the bin angle is set as $10^{\circ}$.

\subsubsection{Classification of contact force}

As mentioned above, soil arching in an embankment is formed by a network of strong contact forces obviously inclining towards the mid-span between piles (Fig. 7), not all contact forces. Meanwhile, larger forces are generally carried by the contacts orientated to the direction of the major principal stress. Hence, a conjecture can be made that, within the "arching zone", the contact with a larger force is mainly inclined to the mid-span between piles. For simplicity, it is necessary to classify the complex contact forces into several groups, in an effort to identify the functions of different constituents of soil arching in an embankment. In this subsection, the complex contact forces within the "arching zone" (Fig. 7) are grouped by the value of $\zeta$, at an interval of 0.1 . Here, $\zeta$ is defined as the ratio of the contact force $f_{\mathrm{c}}$ of a given contact to the mean contact force $\left[f_{\mathrm{c}}\right]$ of the whole assembly, i.e., $\zeta=f_{\mathrm{c}} /\left[f_{\mathrm{c}}\right]$.

Fig. 8 depicts the variation of contact orientations within the "arching zone" (Fig. 7) with $\zeta$. As shown in Fig. 8a, with an increase in $\zeta$, the variation curve of principal direction of contact normal anisotropy $\left(\theta_{\mathrm{c}}\right)$ can be divided into two segments, i.e., $\theta_{\mathrm{c}}>90^{\circ}$ for $\zeta<1.5$, and $\theta_{\mathrm{c}} \leq 90^{\circ}$ for $\zeta \geq 1.5$. Meanwhile, in each segment, $\theta_{\mathrm{c}}$ maintains nearly a constant value. Moreover, Fig. $8 \mathrm{~b}$ shows that with the increase in $\zeta$, the coefficient of contact normal anisotropy $\left(a_{\mathrm{c}}\right)$ tends to decrease at first but then increase. The boundaries $\zeta$ for the two different variation trends are also 1.5. For this reason, the whole network of contact forces can be divided into two parts, namely strong force chain (SFC) and weak force chain (WFC). The former is defined as the force chain with contact forces higher than $1.5\left[f_{\mathrm{c}}\right]$ (i.e., $\zeta \geq 1.5$ ), while the latter has contact forces below $1.5\left[f_{\mathrm{c}}\right]$ (i.e., $\zeta<1.5$ ).

\subsubsection{Functions of SFC and WFC}

The spatial distribution features of contacts are quite different for SFC and WFC (Fig. 8), indicating that the functions of SFC and WFC may be different. To reveal the functions of the two different parts of contact forces in an embankment, statistical measures and treatments are applied for the direction of the major principal stress $\left(\theta_{\max }\right), \theta_{\mathrm{c}}$, and average normal contact force anisotropy $\left(\theta_{\mathrm{n}}\right)$ within the whole domain of the embankment. $\theta_{\max }$ is defined as

$$
\theta_{\max }=\frac{1}{2} \arctan \left(\frac{-2 \sigma_{x y}}{\sigma_{x x}-\sigma_{y y}}\right) \text {, }
$$

where $\sigma_{x x}, \sigma_{x y}$, and $\sigma_{y y}$ are the average stress tensors in the horizontal, tangential, and vertical directions, respectively. These tensors can be gained via a measurement circle (Fig. 2). 
Preliminary statistical results indicate that the distribution of $\theta_{\max }\left(\theta_{\mathrm{c}}\right.$ or $\left.\theta_{\mathrm{n}}\right)$ is approximately the same for unreinforced and geogrid-reinforced cases. Thus, only the statistical results of $\theta_{\max }, \theta_{\mathrm{c}}$, and $\theta_{\mathrm{n}}$ for the unreinforced case with $\Delta s=2.0 \mathrm{~mm}$ are presented (Fig. 9). We assume that the positive direction is in rightward direction from the horizontal direction, and


Fig. 8 Variation of contact orientations within "arching zone" with $\zeta$ : (a) $\theta_{\mathrm{c}}$; (b) $a_{\mathrm{c}}$ the included angle of the oblique line with the horizontal direction in each small square (Fig. 9) represents the value of $\theta_{\max }\left(\theta_{\mathrm{c}}\right.$ or $\left.\theta_{\mathrm{n}}\right)$. Additionally, as shown in Figs. 9b and 9c, the statistical results of $\theta_{\mathrm{c}}$ and $\theta_{\mathrm{n}}$ in SFC are absent within a certain region just below the embankment surface, as almost all contact forces within this region are not included in SFC. Compared with the distribution of $\theta_{\max }$ in the initial state (Fig. 10a), Fig. 9a shows that the rotation of $\theta_{\max }$ is significant within a certain region (i.e., the "arching zone" illustrated in Fig. 7a) above the pile heads. Furthermore, within this region, a portion of $\theta_{\max }$ inclines towards the mid-span between the piles and forms an "arching", whereas the rest of $\theta_{\max }$ rotates towards the model boundary and functions as a support for the "arching". As expected, the rotation of $\theta_{\max }$ upon the "arching zone" is negligible. On the basis of the distribution characteristics of $\theta_{\max }$, the embankment can be divided into two regions (i.e., above and below the "arching") to analyze the different functions of SFC and WFC:

1. Above the "arching". The orientations of $\theta_{\mathrm{c}}$ and $\theta_{\mathrm{n}}$ in SFC (Figs. 9b and 9c) show high consistency, but in WFC $\theta_{\mathrm{c}}$ is approximately perpendicular to $\theta_{\mathrm{n}}$ (Figs. 9d and 9e). More importantly, $\theta_{\mathrm{c}}$ in SFC coincides with $\theta_{\max }$, but $\theta_{\mathrm{c}}$ in WFC does not.

2. Below the "arching". In SFC, $\theta_{\mathrm{c}}$ and $\theta_{\mathrm{n}}$ are gradually aligned in the horizontal direction above the mid-span between piles and both of them are roughly perpendicular to $\theta_{\max }$. However, in WFC, $\theta_{\mathrm{c}}$ shows a reasonable agreement with $\theta_{\max }$, although the distribution of $\theta_{\mathrm{n}}$ is irregular.

Obviously, $\theta_{\mathrm{c}}$ and $\theta_{\mathrm{n}}$ in SFC agree well with the strong contact forces which play a much more

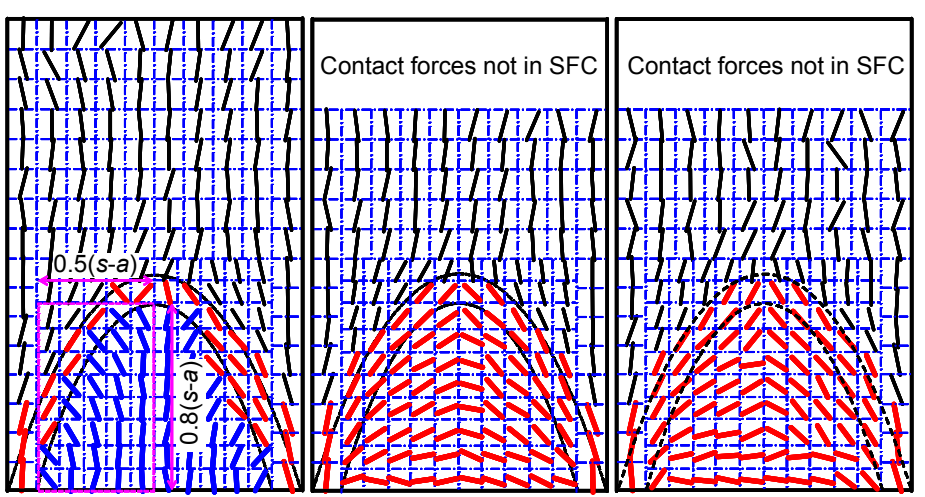

(a) (b)

(c)



(d) (e)

Fig. 9 Distribution of $\theta_{\text {max }}, \theta_{c}$, and $\theta_{\mathrm{n}}$ in unreinforced case with $\Delta s=2.0 \mathrm{~mm}$

(a) Distribution of $\theta_{\max }$ in the initial state; (b) $\theta_{\mathrm{c}}$ in SFC; (c) $\theta_{\mathrm{n}}$ in SFC; (d) $\theta_{\mathrm{c}}$ in WFC; (e) $\theta_{\mathrm{n}}$ in WFC 
important role in forming the "arching". As shown in Figs. 9a, 9b, and 9d, it can be clearly found that the distribution characteristics of $\theta_{\max }$ are a combination of $\theta_{\mathrm{c}}$ distribution in SFC and WFC. Namely, the distribution of $\theta_{\max }$ can comprehensively reflect the distribution characteristics of $\theta_{\mathrm{c}}$ both in SFC and WFC. Practically, the major structure of the "arching" is constructed by the contacts in SFC, while the contacts in WFC serve as the support system for the "arching". In addition, the distribution characteristics of $\theta_{\max }$ can offer a visualization of the "arching". Hence, it will be adopted to depict the "arching" in an embankment in the subsequent analysis.

\subsection{Development of soil arching}

Some existing studies implicitly assumed that the development of soil arching would be completed suddenly. This assumption is inconsistent with the practical situation and cannot explain the variation of soil pressure with $\Delta s$ (Fig. 5). In this section, the development of soil arching in piled embankments will be analyzed in detail.

\subsubsection{Evolution of shape features}

As mentioned before, the distribution of $\theta_{\max }$ is able to comprehensively reflect the distribution of $\theta_{\mathrm{c}}$ in SFC and WFC and can be used to trace the evolution of soil arching in an embankment with $\Delta s$. Meanwhile, the distribution of $\theta_{\max }$ is approximately the same for unreinforced and geogrid-reinforced cases, and therefore, only the statistical results for the unreinforced case with different $\Delta s$ are illustrated in Fig. 10. As shown in Fig. 10a, in the initial stage, the principal direction of stress is basically vertical. As presented in Fig. 10b, the principal direction of stress begins to rotate and forms the "soil arching" when $\Delta s$ occurs. However, note that the so-called "soil arching" at this stage is comprised of two inclined shear planes rather than an arch as $\Delta s$ is relatively small. At the same time, the distribution of the principal direction of stress below the "soil arching" becomes more and more irregular during this process. With a continuous increase in $\Delta s$, the stresses adjust their principal directions and form a "hemisphericalshaped" soil arching (Fig. 10c) as in the model recommended by Hewlett and Randolph (1988). Meanwhile, the distribution of the principal directions of stresses below the soil arching tends to be regular after this stage. Subsequently, as shown in Figs. 10c10f, the soil arching height tends to increase with the increase in $\Delta s$ and finally approaches a maximum soil arching height of $0.8\left(s^{-}-a\right)$. After that, the soil arching maintains a relatively stable state with a nearly constant soil arching height of $0.8(s-a)$ (Figs. 10f10i). Fig. 10 also shows that the region for the rotation of $\theta_{\max }$ (i.e., impact area of soil arching) tends to gradually enlarge with the development of soil arching. For simplicity, the impact area of soil arching can be considered as the soil arching height. After combining the variations of soil pressure (Fig. 5) and soil arching height, the conclusion can be drawn that a higher height of soil arching gives rise to a greater degree of soil arching effect.

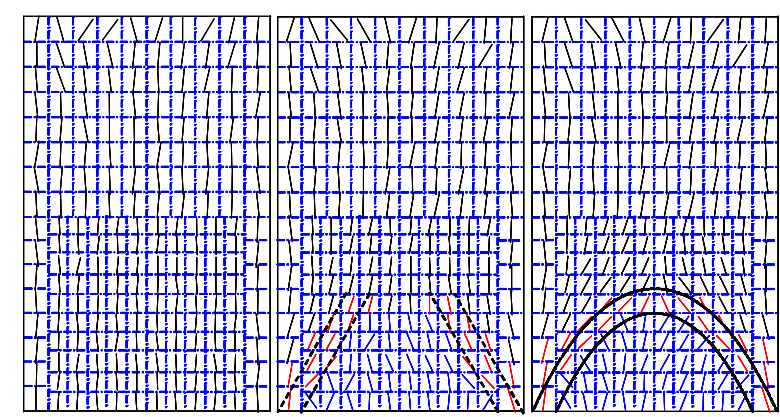

(a) $\Delta s=0.0 \mathrm{~mm}$

(b) $\Delta s=0.3 \mathrm{~mm}$

(c) $\Delta s=0.7 \mathrm{~mm}$

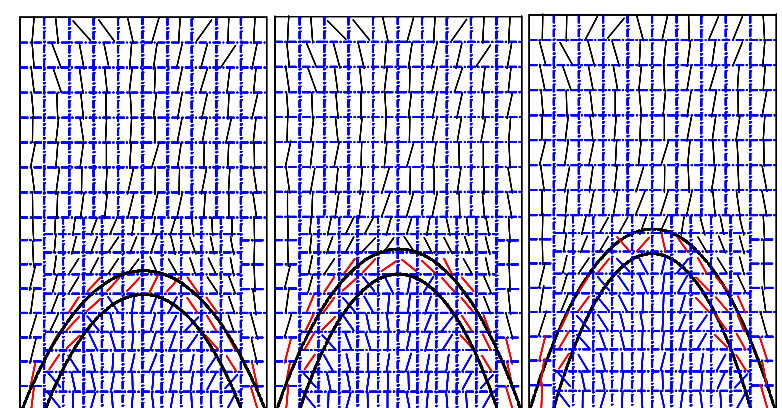

(d) $\Delta s=0.9 \mathrm{~mm}$

(e) $\Delta s=1.2 \mathrm{~mm}$

(f) $\Delta s=1.5 \mathrm{~mm}$

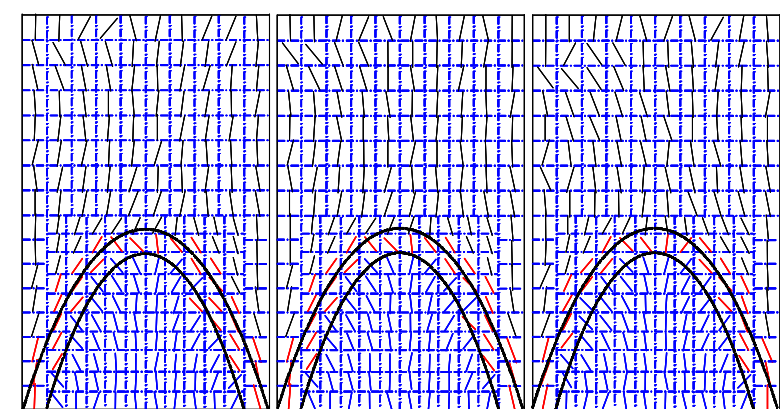

(g) $\Delta s=2.0 \mathrm{~mm}$

(h) $\Delta s=3.0 \mathrm{~mm}$

(i) $\Delta s=30.0 \mathrm{~mm}$

Fig. 10 Evolution of direction of $\theta_{\max }$ in unreinforced case 


\subsubsection{Evolution of contact normal anisotropy}

It has been demonstrated in Section 3.3.2 that the reorientations of $\theta_{\max }, \theta_{\mathrm{c}}$, and $\theta_{\mathrm{n}}$ mainly occur in the "arching zone" and the contacts in SFC are the main component of soil arching. Hence, in this subsection, further investigation on the micro-behaviour of soil arching is performed with the evolution of contact normal anisotropy of SFC in the "arching zone" for unreinforced and geogrid-reinforced cases, as shown in Fig. 11. It can be observed from Fig. 11 that the whole development of contact normal anisotropy for the SFC in the "arching zone" is similar for unreinforced and geogrid-reinforced cases. Specifically, $\theta_{\mathrm{c}}$ decreases gradually with $\Delta s$ and finally approaches a constant value. However, $a_{\mathrm{c}}$ decreases rapidly to a local minimum value and then gradually increases and approaches a constant value. Essentially, the evolving process of soil arching in embankment is the consequence of continuous adjustment of contacts with the $\Delta s$. Combining the variation of soil pressure (Fig. 5) with the evolution of shape feature (Fig. 10) and contact normal anisotropy of SFC in the "arching zone" (Fig. 11), the development of soil arching in piled embankments can be divided into three stages.

Stage 1 (formation of soil arching). Once $\Delta s$ occurs, the relative sliding of embankment fill will arise and thus the particles re-arrange. Due to the rearrangement of particles, the principal direction of contacts will rotate. To be specific, in SFC, $\theta_{\mathrm{c}}$ rotates towards the direction of mid-span between piles (Fig. 10), and hence, the number of contacts decreases in vertical direction and increases in other directions. Thus, as shown in Fig. 11, the decrease in $a_{\mathrm{c}}$ for SFC in "arching zone" is approximately linear with the increase of $\Delta s$ during this stage. Note that, at a small $\Delta s$, only the inclined shear plane, rather than the arch, is formed in the embankment (Fig. 10b), although the soil arching effect has occurred (Fig. 5). With a continuous increase in $\Delta s$, the shear plane evolves into a "hemispherical-shaped" soil arching (Fig. 10c), due to the constant adjustment of the principal direction of contacts. In addition, the rotation is mainly within the height of $0.5(s-a)$ upon the pile head (Figs. 10b and 10c).

Stage 2 (further development of soil arching). With an increase in $\Delta s$, the range for the rotation of contacts evidently enlarges (Figs. 10c-10f), and as a result, more contacts begin to rotate towards the $\mathrm{di}$ - rection of the mid-span between piles. Thus, $\theta_{\mathrm{c}}$ in SFC continues to decrease with the increase in $\Delta s$ (Fig. 11). However, the variation of $a_{\mathrm{c}}$ in SFC is found to increase gradually with $\Delta s$, meaning that, in SFC, the number of contacts mainly increases in the corresponding principal direction of anisotropy. During this process, the height of soil arching (Fig. 10) and the degree of soil arching effect (Fig. 5) increase gradually with $\Delta s$.

Stage 3 (relatively stable stage of soil arching). With a further increase in $\Delta s$, for the SFC in the "arching zone", the number of contacts remains relatively stable. Thus, as shown in Fig. $11, \theta_{\mathrm{c}}$ and $a_{\mathrm{c}}$ in SFC remain nearly constant, indicating that the soil arching in a piled embankment is in a relatively stable state at this stage.

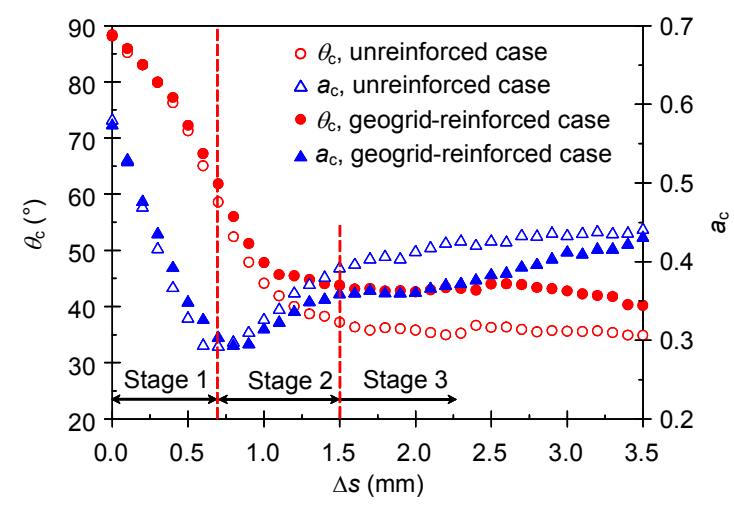

Fig. 11 Variation of contact normal anisotropy of SFC in "arching zone" for unreinforced and geogrid-reinforced cases

In summary, $\Delta s$ has a significant influence on the formation and features of soil arching in piled embankments with or without geosynthetic reinforcement, and the maximum soil arching height is approximately $0.8(s-a)$ in this study. Meanwhile, the numerical results also show that the macro- and micro-behaviours (e.g., particle motion, contact force, and fabric anisotropy) are approximately similar for piled embankments with or without geosynthetic reinforcement at each stage. This finding indicated that the presence of geosynthetic has a negligible influence on the formation and features of soil arching in a piled embankment when $\Delta s$ for both cases are identical. Meanwhile, note that in practice, for a piled embankment with geosynthetic reinforcement, the development of soil arching will be slowed down due 
to the reduction of $\Delta s$ by the geosynthetic reinforcement, and it would be definitely completed with sufficient $\Delta s$.

\section{Parametric study of soil arching without geosynthetic reinforcement}

Parametric study is necessarily conducted to further understand the evolution of soil arching in a piled embankment and its governing factors. In this section, the unreinforced case is selected as the benchmark, and the effects of some practically important factors (e.g., friction coefficient of embankment fill, embankment height, pile clear spacing, and relative density of embankment fill) on the development of soil arching are investigated. Additionally, many indices can be used to indirectly characterize the degree of the soil arching effect. One representative parameter, the efficacy of the embankment, is adopted as an indicator to evaluate the applicability of the numerical model established in preceding sections. As defined by Hewlett and Randolph (1988), the efficacy $E$ can be expressed as

$$
E=\frac{F_{\mathrm{p}}}{W},
$$

where $F_{\mathrm{p}}$ is the load applied on the pile, and $W$ is the weight of a mat slice of length $s$, i.e., the pile spacing of a pied embankment. The larger the value of $E$, the greater the soil arching effect. If no soil arching effect occurs in the embankment, the value of $E$ is equal to the capping ratio, $\alpha$, i.e.,

$$
\alpha=\frac{a}{s},
$$

where $a$ is the width of the pile.

\subsection{Friction coefficient of embankment fill}

Some laboratory model tests (van Eekelen et al., 2012a; 2012b) and numerical simulations using continuum models (Jenck et al., 2007; Benmebarek et al., 2015) have demonstrated that the macroscopic friction angle of the embankment fill has a significant effect on the load-transfer efficacy of an embankment. For a given particle size distribution in DEM, the macroscopic friction angle (e.g., $\varphi_{\max }$ ) of an assembly is unique, which can be determined by the microscopic friction coefficient $(f)$, and the relation between $\varphi_{\max }$ and $f$ can be calibrated by numerical biaxial tests (Section 2.3.1). Specifically, the variation of $\varphi_{\max }$ with $f$ is found to follow a logarithmic relation (i.e., $\varphi_{\max }=6.82 \ln f+49.50$ ) by the numerical biaxial tests (Fig. 3) in this study. As expected, the microscopic friction coefficient of embankment fill has a great influence on the load-transfer efficacy of an embankment, as shown in Fig. 12. An increase of $f$ from 0.1 to 0.9 leads to an increase of the maximum efficacy from $43 \%$ to $78 \%$, even though the soil arching heights are more or less identical in each case, as depicted in Fig. 13. A tentative inference from this result is that the friction coefficient of the embankment fill has a significant effect on the load-transfer between the soil arching and the embankment fill below the arching, but not the soil arching height. Meanwhile, Fig. 12 also shows that the threshold value of $\Delta s$ where the efficacy reaches the maximum is approximately the same for each case. So the friction coefficient of embankment fill has a negligible influence on the formation and features of soil arching. In addition, note that a point of sudden change can be observed with each case (Fig. 12), which may be related to the failure of soil arching, and the critical $\Delta s$ where the efficacy changes abruptly tends to increase with the increase of $f$. This indicates that the friction coefficient (corresponding to the friction angle in the macroscopic scale) of embankment fill has a significant effect on the stability of soil arching in embankments.

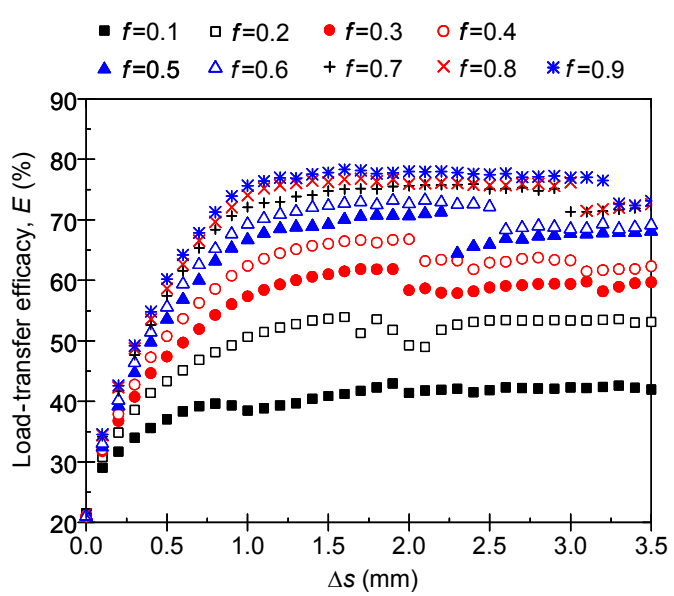

Fig. 12 Effect of friction coefficient $f$ of embankment fill on efficacy 


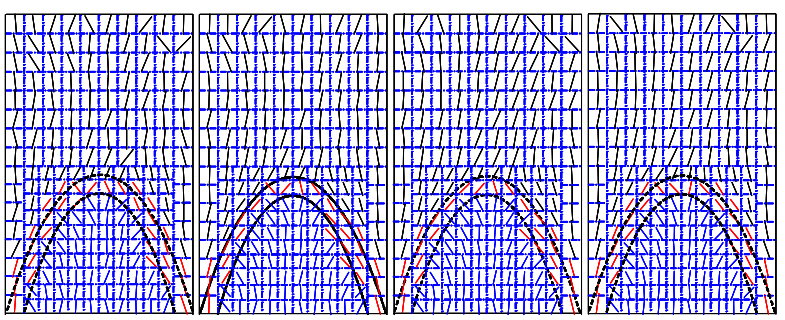

(a) $f=0.2$ (c) $f=0.6$

(d) $f=0.8$

Fig. 13 Distribution of $\theta_{\max }$ with different friction coefficients $f$ of embankment fill at $\Delta s=2.0 \mathrm{~mm}$

\subsection{Embankment height}

In practice, it is necessary to have sufficient embankment height to ensure that localized differential settlement cannot occur at the surface of the embankment, which implicitly indicates that the embankment height is another key factor governing the formation and features of soil arching in an embankment. It is evident in Fig. 14 that an embankment shows greater efficacy, the higher it is. More importantly, note that, when the height is less than $420 \mathrm{~mm}$ (i.e., $0.7(s-a)$ ), the efficacy reaches a maximum at $\Delta s=0.1 \mathrm{~mm}$, and then maintains an almost constant value. Since the height is less than $420 \mathrm{~mm}$ (i.e., $0.7(s-a)$ ), the embankment height is relatively low and only an inclined shear plane, rather than an arch, can be formed in the embankment as shown in Fig. 15a. When $420 \mathrm{~mm} \leq h \leq 840 \mathrm{~mm}$ (i.e., $0.7\left(s^{-}-a\right) \leq$ $h \leq 1.4(s-a)$ ), the efficacy increases gradually and obtains a relatively constant value after $\Delta s$ exceeds a certain value. As presented in Figs. $15 \mathrm{~b}$ and



Fig. 14 Effect of embankment height on efficacy

$15 \mathrm{c}$, when $420 \mathrm{~mm} \leq h \leq 840 \mathrm{~mm}$ (i.e., $0.7(s-a) \leq h \leq$ $1.4(s-a)$ ), the embankment height is sufficient for partial arching but still insufficient for the formation of full arching. After the height is greater than $840 \mathrm{~mm}$ (i.e., $h>1.4(s-a)$ ), the effect of embankment height on the critical $\Delta s$, where the efficacy changes abruptly, can be ignored (Fig. 14), as the embankment height is sufficient for the formation of full arching and the soil arching heights are more or less the same in each case (Figs. 15d and 15e). The embankment height is thus another key factor governing the formation and features of soil arching in embankments.

Meanwhile, the laboratory model test results (Chen et al., 2008) indicated that the critical height of an embankment for differential settlement on the embankment surface is about 1.4 times the pile clear spacing. This result agrees well with the boundary of the embankment height for partial arching and full arching in this study. Thus, the conclusion can be drawn that full arching is able to prevent the occurrence of differential settlement on the embankment surface, but partial arching will not.

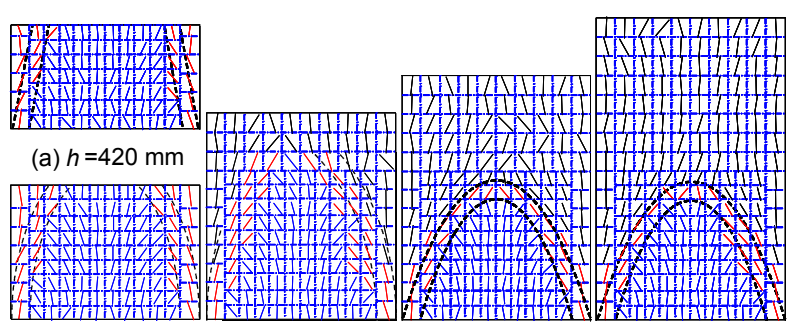

$\begin{array}{llll}\text { (b) } h=540 \mathrm{~mm} & \text { (c) } h=840 \mathrm{~mm} & \text { (d) } h=960 \mathrm{~mm} & \text { (e) } h=1200 \mathrm{~mm}\end{array}$

Fig. 15 Distribution of $\theta_{\max }$ with different embankment heights at $\Delta s=2.0 \mathrm{~mm}$

\subsection{Pile clear spacing}

Actually, pile clear spacing is an important design parameter in piled embankments, as it has significant influence on the construction cost and efficacy of embankments. Fig. 16 depicts the variation curves of efficacy versus $\Delta s$ for different pile clear spacings. As expected, a smaller pile clear spacing gives rise to a greater efficacy of embankment. However, note that the critical $\Delta s$ where the efficacy reaches its maximum value decreases. In other words, for an embankment with a smaller pile clear spacing, a smaller $\Delta s$ is needed for the formation of soil arching in the embankment. However, as shown in 
Fig. 17, the maximum arching height is approximately equal to $0.8(s-a)$ for each case. Hence, a conclusion can be drawn that pile clear spacing has a significant influence on the formation of soil arching, but not on its features.

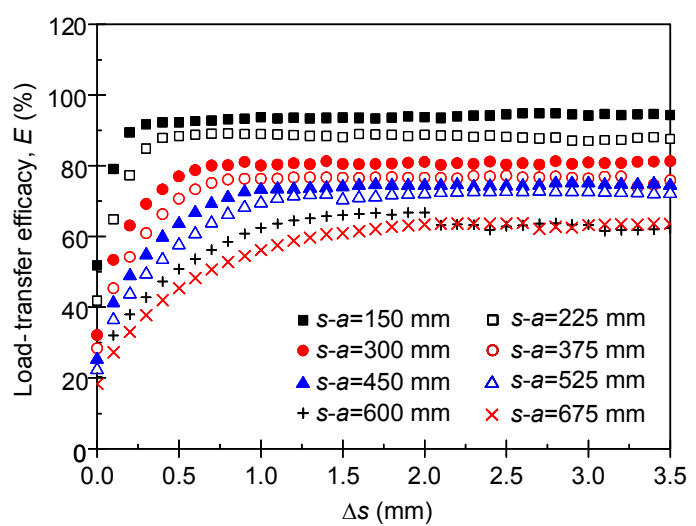

Fig. 16 Effect of pile clear spacing on efficacy

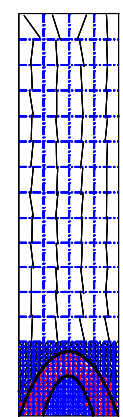

(a)

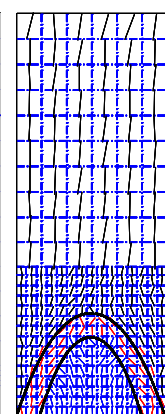

(b)



(c)

(d)
Fig. 17 Distribution of $\theta_{\max }$ with different pile clear spacings at $\Delta s=2.0 \mathrm{~mm}$ : (a) $s-a=150 \mathrm{~mm}$; (b) $s^{-a}=300 \mathrm{~mm}$; (c) $s-a=450 \mathrm{~mm} ;$ (d) $s-a=600 \mathrm{~mm}$

\section{Conclusions}

In this study, a series of 2D DEM numerical simulations have been conducted to investigate the formation and features of soil arching in piled embankments with or without geosynthetic reinforcement with an increase in $\Delta s$. Based on the analysis and discussion of the results, the following conclusions can be drawn.

$\Delta s$ has a significant influence on the formation and features of soil arching in piled embankments with or without geosynthetic reinforcement. Soil arching in embankments is formed by the SFC with contact forces above 1.5 times mean contact force $\left(1.5\left[f_{\mathrm{c}}\right]\right)$ of the whole assembly, while the WFC acts as a support system. At smaller $\Delta s$, the "soil arching" is comprised of two inclined shear planes rather than an arch. Then, with an increase in $\Delta s$, the inclined shear plane is transformed into a hemispherical soil arch, due to the rotation of the principal directions of contacts and forces. With a further increase in $\Delta s$, the height of the hemispherical soil arching gradually increases. Finally, the height approaches the maximum value of $0.8(s-a)$, and then maintains a relatively stable state within the $\Delta s$ range of interest in this study. For a given case, a greater height of soil arching gives rise to a greater degree of soil arching effect. However, the presence of geosynthetic has a negligible influence on the formation and features of soil arching if $\Delta s$ are identical for both geosynthetic reinforced and unreinforced cases.

Parametric studies indicate that the friction coefficient (corresponding to the friction angle on the macroscopic scale) of embankment fill has a negligible influence on the formation and features of soil arching, although it has a significant influence on the degree of the soil arching effect. As expected, the degree of the soil arching effect increases gradually with the embankment height. Meanwhile, note that the embankment height is a key factor governing the formation and features of soil arching. To be specific, only two shear planes are formed if $h<0.7(s-a)$, a partial arching is formed if $0.7(s-a) \leq h \leq 1.4(s-a)$, and a full arching is formed if $h>1.4(s-a)$. In addition, a smaller pile clear spacing gives rise to a greater degree of soil arching effect. The pile clear spacing has a significant effect on the formation of soil arching, but not on its features.

Further studies using 3D model tests and numerical simulations are required and would be useful to investigate the validity of the findings in this study. Meanwhile, more research is needed on the influence of piles arranged in various patterns (such as square pattern and equilateral triangular pattern) on the formation and features of soil arching in the 3D case.

\section{References}

Bathurst, R.J., Rothenburg, L., 1990. Observations on stress-force-fabric relationships in idealized granular materials. Mechanics of Materials, 9(1):65-80. http://dx.doi.org/10.1016/0167-6636(90)90030-J 
Benmebarek, S., Berrabah, F., Benmebarek, N., 2015. Effect of geosynthetic reinforced embankment on locally weak zones by numerical approach. Computers and Geotechnics, 65:115-125. http://dx.doi.org/10.1016/j.compgeo.2014.12.004

Bhandari, A., Han, J., 2010. Investigation of geotextile-soil interaction under a cyclic vertical load using the discrete element method. Geotextiles and Geomembranes, 28(1): 33-34.

http://dx.doi.org/10.1016/j.geotexmem.2009.09.005

Bolton, M.D., 1986. The strength and dilatancy of sands. Géotechnique, 36(1):65-78. http://dx.doi.org/10.1680/geot.1986.36.1.65

Briançon, L., Simon, B., 2012. Performance of pile-supported embankment over soft soil: full-scale experiment. Journal of Geotechnical and Geoenvironmental Engineering, 138(4):551-561. http://dx.doi.org/10.1061/(asce)GT.1943-5606.0000561

Carlson, B.O., 1987. Reinforced Soil, Principles for Calculation. Terratema AB, Linköping, Sweden (in Swedish).

Chen, R.P., Xu, Z.Z., Chen, Y.M., et al., 2010. Field tests on pile-supported embankment over soft ground. Journal of Geotechnical and Geoenvironmental Engineering, 136(6):777-785. http://dx.doi.org/10.1061/(asce)GT.1943-5606.0000295

Chen, R.P., Zhao, X., Wang, Z.Z., et al., 2013. Experimental study on dynamic load magnification factor for ballastless track-subgrade of high-speed railway. Journal of Rock Mechanics and Geotechnical Engineering, 5(4):306-311. http://dx.doi.org/10.1016/j.jrmge.2013.04.004

Chen, R.P., Chen, J.M., Wang, H.L., et al., 2014. Recent research on the track-subgrade of high-speed railways. Journal of Zhejiang University-SCIENCE A (Applied Physics \& Engineering), 15(12):1034-1038. http://dx.doi.org/10.1631/jzus.A1400342

Chen, R.P., Wang, Y.W., Ye, X.W., et al., 2016. Tensile force of geogrids embedded in pile-supported reinforced embankment: a full-scale experimental study. Geotextiles and Geomembranes, 44(2):157-169.

http://dx.doi.org/10.1016/j.geotexmem.2015.08.001

Chen, Y.M., Cao, W.P., Chen, R.P., 2008. An experimental investigation of soil arching within basal reinforced and unreinforced piled embankments. Geotextiles and Geomembranes, 26(2):164-174. http://dx.doi.org/10.1016/j.geotexmem.2007.05.004

Gabr, M., Han, J., 2005. Geosynthetic reinforcement for soft foundations: US perspectives. International Perspectives on Soil Reinforcement Applications, Austin, USA, p.1-17. http://dx.doi.org/10.1061/40788(167)5

Guido, V.A., Kneuppel, J.D., Sweeny, M.A., 1987. Plate loading tests on geogrid-reinforced earth slabs. Proceedings of the Geosynthetics, New Orleans, USA, p.216-225.

Han, J., Gabr, M.A., 2002. A numerical study of load transfer mechanisms in geosynthetic reinforced and pile supported embankments over soft soil. Journal of Geotech- nical and Geoenvironmental Engineering, 128(1):44-53. http://dx.doi.org/10.1061/(asce)1090-0241(2002)128:1(44)

Han, J., Bhandari, A., Wang, F., 2012. DEM analysis of stresses and deformations of geogrid-reinforced embankments over piles. International Journal of Geomechanics, 12(4):340-350. http://dx.doi.org/10.1061/(asce)GM.1943-5622.0000050

Hewlett, W.J., Randolph, M.F., 1988. Analysis of piled embankment. Ground Engineering, 21(3):12-18.

Itasca, 2008. Particle Flow Code in Two Dimensions, Version 4.0. Itasca Consulting Group, Inc., Minnesot, USA.

Jenck, O., Dias, D., Kastner, R., 2007. Two-dimensional physical and numerical modeling of a pile-supported earth platform over soft soil. Journal of Geotechnical and Geoenvironmental Engineering, 133(3):295-305. http://dx.doi.org/10.1061/(asce)1090-0241(2007)133:3(295)

Jenck, O., Dias, D., Kastner, R., 2009. Discrete element modelling of a granular platform supported by piles in soft soil -validation on a small scale model test and comparison to a numerical analysis in a continuum. Computers and Geotechnics, 36(6):917-927. http://dx.doi.org/10.1016/j.compgeo.2009.02.001

Kempfert, H.G., Stadel, M., Zaeske, D., 1997. Berechnung von geokunstst off between trags chichten über pfahlelementen. Bautechnik, 74:818-825 (in German).

Lai, H.J., Zheng, J.J., Zhang, J., et al., 2014. DEM analysis of "soil"-arching within geogrid-reinforced and unreinforced pile-supported embankments. Computers and Geotechnics, 61:13-23. http://dx.doi.org/10.1016/j.compgeo.2014.04.007

Ling, X.Z., Wang, L.N., Zhang, F., et al., 2010. Field experiment on train-induced embankment vibration responses in seasonally-frozen regions of Daqing, China. Journal of Zhejiang University-SCIENCE A (Applied Physics \& Engineering), 11(8):596-605. http://dx.doi.org/10.1631/jzus.A0900657

Liu, S.Y., Du, Y.J., Yi, Y.L., et al., 2012. Field investigations on performance of T-shaped deep mixed soil cement column-supported embankments over soft ground. Journal of Geotechnical and Geoenvironmental Engineering, 138(6):718-727. http://dx.doi.org/10.1061/(asce)GT.1943-5606.0000625

Lu, W.H., Miao, L.C., 2015. A simplified 2-D evaluation method of the arching effect for geosynthetic-reinforced and pile-supported embankments. Computers and Geotechnics, 65:97-103. http://dx.doi.org/10.1016/j.compgeo.2014.11.014

MOT (Ministry of Transport of the People's Republic of China), 1999. Test Methods of Geosynthetics for Highway Engineering, JTJ/T 060-98. China Communications Press, Beijing, China (in Chinese).

Rothenburg, L., Bathurst, R.J., 1989. Analytical study of induced anisotropy in idealized granular materials. Géotechnique, 39(4):601-614. http://dx.doi.org/10.1680/geot.1989.39.4.601

Rui, R., van Tol, F., Xia, X.L., et al., 2016a. Evolution of soil 
arching; 2D DEM simulations. Computers and Geotechnics, 73:199-209.

http://dx.doi.org/10.1016/j.compgeo.2015.12.006

Rui, R., van Tol, A.F., Xia, Y.Y., et al., 2016b. Investigation of soil-arching development in dense sand by 2D model tests. Geotechnical Testing Journal, 39(3):415-430. http://dx.doi.org/10.1520/GTJ20150130

Terzaghi, K., 1943. Theoretical Soil Mechanics. Wiley, New York, USA. http://dx.doi.org/10.1002/9780470172766

van Eekelen, S.J.M., Bezuijen, A., Lodder, H.J., et al., 2012a. Model experiments on piled embankments. Part I. Geotextiles and Geomembranes, 32:69-81.

http://dx.doi.org/10.1016/j.geotexmem.2011.11.002

van Eekelen, S.J.M., Bezuijen, A., Lodder, H.J., et al., 2012b. Model experiments on piled embankments. Part II. Geotextiles and Geomembranes, 32:82-94.

http://dx.doi.org/10.1016/j.geotexmem.2011.11.003

van Eekelen, S.J.M., Bezuijen, A., van Tol, A.F., 2013. An analytical model for arching in piled embankments. $\mathrm{Ge}$ otextiles and Geomembranes, 39:78-102. http://dx.doi.org/10.1016/j.geotexmem.2013.07.005

van Eekelen, S.J.M., Bezuijen, A., van Tol, A.F., 2015. Validation of analytical models for the design of basal reinforced piled embankments. Geotextiles and Geomembranes, 43(1):56-81. http://dx.doi.org/10.1016/j.geotexmem.2014.10.002

Wang, C., Xu, Y., Dong, P., 2014. Working characteristics of concrete-cored deep cement mixing piles under embankments. Journal of Zhejiang University-SCIENCE A (Applied Physics \& Engineering), 15(6):419-431. http://dx.doi.org/10.1631/jzus.A1400009

Wang, Z.J., Jacobs, F., Ziegler, M., 2014. Visualization of load transfer behaviour between geogrid and sand using $\mathrm{PFC}^{2 \mathrm{D}}$. Geotextiles and Geomembranes, 42(2):83-93. http://dx.doi.org/10.1016/j.geotexmem.2014.01.001

Wang, Z.J., Jacobs, F., Ziegler, M., 2016. Experimental and DEM investigation of geogrid-soil interaction under pullout loads. Geotextiles and Geomembranes, 44(3): 230-246. http://dx.doi.org/10.1016/j.geotexmem.2015.11.001

Zaeske, D., Kempfert, H., 2002. Calculation and behaviour of unreinforced and reinforced bearing layers over point- or lineshaped bearing elements. Bauingenieur, 77(2): 01195104 (in German).

Zhang, J., Zheng, J.J., Chen, B.G., et al., 2013. Coupled mechanical and hydraulic modelling of a geosyntheticreinforced and pile-supported embankment. Computers and Geotechnics, 52:28-37.

http://dx.doi.org/10.1016/j.compgeo.2013.03.003

\section{中文概要}

题 目: 桩承式路堤中土拱结构的形成与形态特征离散元 数值分析

目 的: 旨在从宏细观角度探究桩承式路堤中土拱结构的 形态特征及其演化规律。

创新点: 1. 基于接触力链网络的细观统计与分析并结合土 拱结构的特点, 对路堤中的接触力链进行划分;

2. 从宏细观角度, 揭示路堤中土拱结构的形态特 征, 并研究土拱结构随桩土相对位移增加的演化 规律。

方 法: 1. 采用傅里叶级数近似法对接触力链组构各向异 性进行统计与划分； 2. 基于路堤填料位移、接触 力分布以及组构各向异性主方向等的分布及变 化规律, 从宏细观角度对土拱结构的形态及其演 化规律进行综合分析。

结 论: 1 . 土拱结构是由路堤中大于 1.5 倍接触力均值的 强力链构成, 而弱力链则主要起支撑作用。2. 土 拱结构随桩土相对位移的增加而历经倾斜剪切 面 $\rightarrow$ 半圆形拱 $\rightarrow$ 悬链线形拱的演化规律, 土拱结 构的最大高度约为 0.8 倍桩净间距。3. 路堤填料 内摩擦角对土拱结构的形态及演化规律几乎无 影响; 路堤填筑高度对土拱结构形态则有显著影 响; 桩净间距对土拱结构的演化有一定影响, 但 是对其最终形态特征则几乎无影响。

关键词: 桩承式路堤; 数值模拟; 离散元法; 土拱结构; 形成; 形态特征 